\section{Crusades and rackets}

\author{
John Galloway
}

Vitamin C and Cancer: Medicine or Politics. By Evelleen Richards. St Martin's Press/Macmillan: 1991. Pp. 269. \$35, £35.

I HAVE spoken to Linus Pauling just once - in the mid-1970s when I was secretary of the Medical Research Council's Cancer Therapy Committee. His son Peter, whom I knew slightly from a chance meeting years before, used me to ask the committee if they would be prepared to carry out a trial of vitamin C as a treatment for cancer. One afternoon I answered the phone and a voice said, "My name is Linus Pauling, I think you know my son." It was a disarming opening. But it was going to take more than that to get what he wanted.

In the event the committee decided against a trial, seeing no particularly compelling reason to do one. Pauling must have been disappointed. I know I was, feeling that if Pauling thought it was a good idea then it probably was. And, having spent some years working on collagen and being interested in its crosslinking, it seemed there was enough of a possible mechanism by which vitamin C might inhibit the spread of cancer - by toughening up the connective tissue - to warrant a trial.

That episode represented, in miniature, the struggle that has now engaged Pauling for more than 20 years. Obsessed by his belief that vitamin $\mathrm{C}$ is good for cancer patients, he has spent two decades trying to persuade what he sees as the American medical establishment to take his belief seriously. For their part, judging by Richards' book, they believe they have, having weighed his idea in the balance of the randomized clinical trial but found it wanting.

At one level, Richards' book is a straightforward piece of historical narrative, telling it how it was, and is, because the story is presumably not over; from Pauling's early contact with Ewan Cameron, a Scottish surgeon who triggered the whole thing, through to and beyond the clinical trials carried out by the Mayo Clinic with their conclusion that there was nothing in the idea. This conclusion was followed by an avalanche of acrimony - of accusations and counter-accusations of sharp practice, unprofessional conduct, of bringing science and medicine into disrepute, and of threats of litigation. As Richards cheer- fully says, it is a story that has everything. Well, nearly everything. It doesn't seem to have an ending. Is Vitamin C good for cancer patients or not? But, of course, that does not really matter because Richards is simply using the saga to take the lid off medicine and medical science.

She tries - and with considerable success - to give us insights into how new ideas are accepted and become part

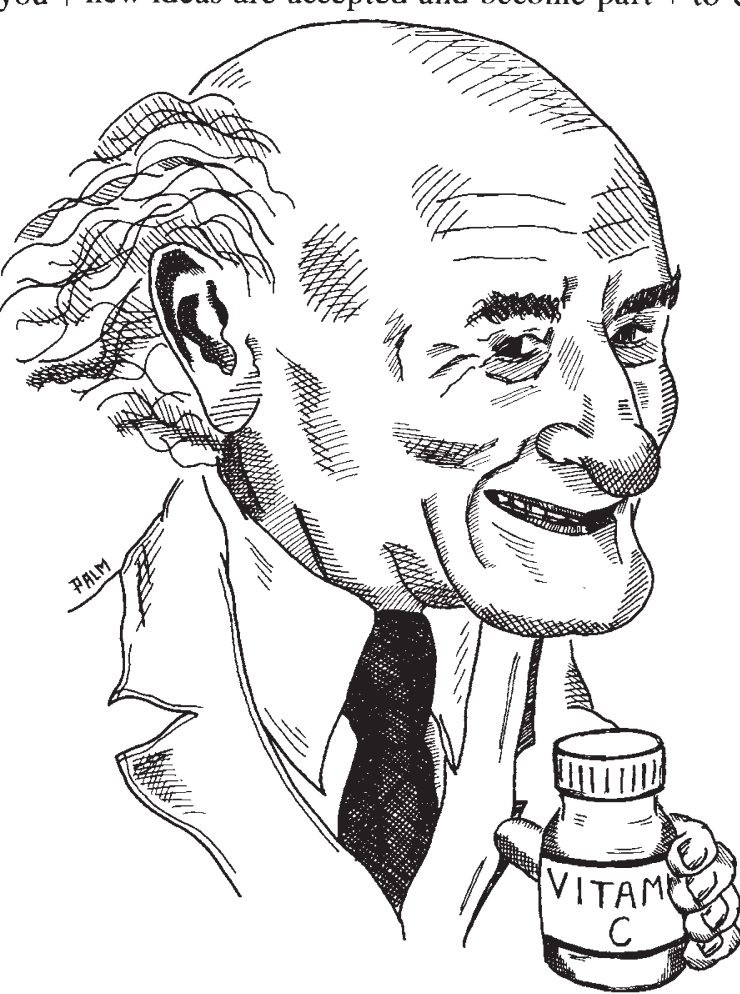

of the medicine of the day, or aren't and don't. And because the two Mayo Clinic trials figured so largely in generating and sustaining the particular drama, Richards hooks her arguments onto the idea of the clinical trial put forward as the paradigm for how these choices are made. It is a well researched book as far as I can judge, and a well written one, and it addresses an intriguing and complicated question.

But I could not help thinking that it missed a point. The history of randomized clinical trials is not really a history of established medical practice setting to exclude outsiders. On the contrary, a great deal of the struggle surrounding trials has been between statisticians who saw potential value in randomized trials and doctors who often did not, or who itself up with this particular methodology simply misunderstood them, even seeing them as an intrusion into the way they practised. There is an issue central to medicine here: the tension between a doctor practising on the basis of his or her own personal clinical experience, and practising on the basis of someone else's, which they can be reluctant to do. The irony running through the book is that the medical establishment were behaving more like statisticians whereas Pauling was behaving more like a traditional doctor.

What seems to matter most in clinicaltrial methodology is that there is at the outset real interest by doctors in the question that is being addressed. This ensures that the trial is large enough to provide an answer sufficiently clear and to convince both them and others of its value. Richards makes an interesting story in comparing inconsistent attitudes to trials of vitamin $\mathrm{C}$ and the anticancer drug 5-fluorouracil. But she could have looked at other examples. Massive clinical trials have shown convincingly that aspirin is of value in warding off strokes, heart attacks and pregnancyinduced high blood pressure, and also that its use is often preferable to much more expensive and well publicized drugs such as streptokinase. It has not been so difficult to persuade large numbers of doctors to join in these enterprises and come up with an answer they take seriously - and act on.

There is at least some evidence that a lot of publicity tends to accompany only those trials involving a clash of what are represented as different medical cultures. It is worth noting that when it was begun, the Medical Research Council's trial of vitamins to prevent spina bifida aroused considerable passion. Its recently published finding that folic acid would prevent the majority of cases has passed fairly quietly. Would this have been the case had the trial come down against the compound?

Richards is at pains to tell us that however good a drama the story provides, she is really interested in what it tells us about medicine. But the fact remains that she has chosen an extreme case to make her point because she believes it makes it most clearly. And it is a very good story.

John Galloway (formerly with the Cancer Research Campaign) is at 54 Windmill Drive, Croxley Green, Hertfordshire, WD3 3FE, UK.

Just published by the Royal Society of Chemistry is Vitamin $C$ : Its Chemistry and Biochemistry by Michael B. Davis, John Austin and David A. Partridge. Price is $£ 13.50$ (pbk). 